\title{
PELATIHAN GMP DAN HACCP BAGI PENGRAJIN GULA KELAPA KRISTAL
}

\section{GMP AND HACCP TRAINING FOR CRAFTSMEN COCONUT SUGAR CRYSTAL}

\author{
Watemin $^{1)}$, Agus Mulyadi Purnawanto ${ }^{2)}$, dan Anwar Ma'ruf ${ }^{3)}$ \\ ${ }^{1}$ Program Studi Agribisnis, ${ }^{2}$ Program Studi Agroteknologi, ${ }^{3}$ Program Studi Teknik Kimia \\ Universitas Muhammadiyah Purwokerto \\ Jl. Raya Dukuhwaluh PO Box 202 Purwokerto 53182 \\ 1)email: watemyn@ump.ac.id
}

\begin{abstract}
ABSTRAK
Kegiatan ini bertujuan untuk meningkatkan pengetahuan dan ketrampilan petani tentang pembuatan gula kelapa kristal yang memenuhi standar Good Manufacturing Practice (GMP) dan Hazard Analysis and Critical Control Points (HACCP). Metode kegiatan yang digunakan adalah ceramah dan praktek. Hasil kegiatan menunjukkan bahwa : 1). Pemahaman pengrajin mengenai pentingnya usaha bersama dalam satu kelompok sudah baik, 2). Pengetahuan pengrajin mengenai aspek GMP dan HACCP sudah baik, 3). Penerapan GMP dan HACCP dalam industri gula kelapa kristal yang dilakukan oleh pengrajin pada KUB Rengganis Desa Karangjengkol belum sepenuhnya dapat dilaksanakan karena adanya berbagai keterbatasan yang dimiliki oleh para pengrajin.
\end{abstract}

Kata kunci: kewirausahaan, Good Manufacturing Practice, Hazard Analysis and Critical Control Points

\section{ABSTRACT}

This activity aims to increase knowledge and farmers' skill about the making of coconut sugar crystals that meet the standards of Good Manufacturing Practice (GMP) and Hazard Analysis and Critical Control Points (HACCP). Activity methods used are lectures and practical. The results showed that the activity: 1). Craftsmen understanding of the importance of joint ventures in the group is good, 2). Knowledge of craftsmen GMP and HACCP are good, 3). Implementation of GMP and HACCP at the industry of palm sugar crystals made by craftsmen on the Village Karangjengkol can not be fully implemented because of various limitations that are owned by the craftsmen.

Keywords : entrepreneurship, Good Manufacturing Practice, Hazard Analysis and Critical Control Points

Submited : 28 Oktober $2016 \quad$ Revisied : 15 Nopember 2016 Accepted : 21 Januari 2017

\section{PENDAHULUAN}

Gula merupakan produk yang sangat dibutuhkan dalam kehidupan manusia. Penggunaan gula sebagai bahan pemanis hampir setiap hari digunakan dalam kehidupan manusia. Gula sebagai bahan pemanis digunakan langsung oleh rumah tangga maupun oleh industri. Penggunaan gula tersebut umumnya digunakan untuk pembuatan makanan dan minuman. Pada tahun 2014 kebutuhan akan gula untuk dikonsumsi diperkirakan mencapai 5,700 juta ton, yang terdiri dari 2,96 juta ton untuk konsumsi rumah tangga dan 2,74 juta ton untuk konsumsi industri. Sementara itu pada tahun 2013 produksi gula nasional hanya mencapai 2,55 juta ton. Berdasar data tersebut maka kebutuhan akan gula nasional untuk tahun 2014 sangat kekurangan banyak.

Untuk memenuhi akan kekurangan gula maka dapat dilakukan upaya peningkatan 
Watemin, Agus Mulyadi Purnawanto \& Anwar Ma'ruf, Pelatihan GMP dan HACCP Bagi Pengrajin Gula Kelapa Kristal

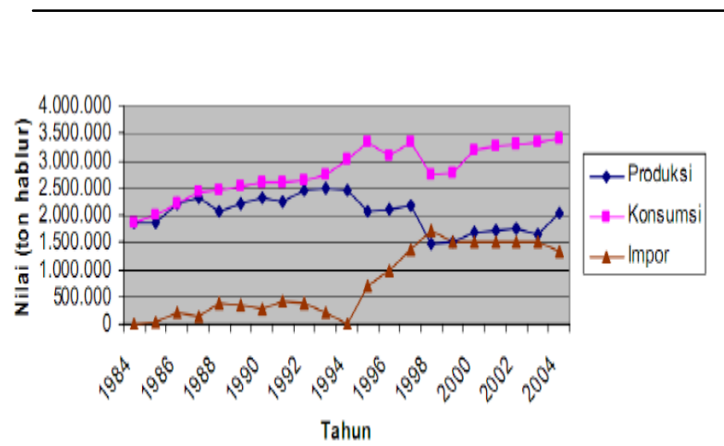

Grafik. Perkembangan Produksi,

Konsumsi, dan Impor Gula (Sumber :

Yusuf, $d k k .$, 2010).

produksi gula secara nasional. Akan tetapi untuk meningkatkan produksi gula secara nasional biaya produksi yang harus dikeluarkan sebesar Rp.11.000/kg. Sementara itu harga jual gula di pasaran hanya sebesar Rp.9.000/kg. Dengan demikian untuk meningkatkan produksi gula secara nasional maka harus mengorbankan biaya produksi yang lebih besar dari harga jual produk yang akan dicapai.

Gula kelapa sebagai produk pemanis yang dibuat dari bahan alami, khususnya nira kepala kelapa biasanya diproduksi oleh pengrajin rumah tangga yang belum memenuhi standar minimal yang telah ditetapkan. Penerapan Good Manufacturing Practices (GMP), dan Hazard Analysis and Critical Control Points (HACCP) dalam proses produksi sangat diperlukan untuk tetap menjaga agar kualitas produk yang dihasilkan memenuhi standar minimal tersebut. Adapun persyaratan minimal kualitas gula kelapa kristal menurut SNI (SII 0268-85) tertera pada tabel 1.

Tabel 1. Persyaratan Minimal Gula Kelapa Kristal Sesuai SNI (SII 0268-85)

\begin{tabular}{ll}
\hline Komponen & Kadar \\
\hline $\begin{array}{l}\text { Gula (jumlah sakarosa } \\
\text { dan gula reduksi) (\%) }\end{array}$ & Min. 80,0 \\
Sakarosa (\%) & Min, 75,0 \\
Gula reduksi (\%) & Maks. 6,0 \\
Air (\%) & Maks. 3,0 \\
Abu (\%) & Maks. 2,0
\end{tabular}

\begin{tabular}{ll}
$\begin{array}{l}\text { Bagian-bagian tak larut } \\
\text { dalam air }(\%)\end{array}$ & Maks. 1,0 \\
$\begin{array}{l}\text { Zat warna } \\
\text { Logam berbahaya }(\mathrm{Cu},\end{array}$ & Yang diizinkan \\
$\mathrm{Hg}, \mathrm{Pb}, \mathrm{As})$ & Negatif \\
Pati & $\begin{array}{l}\text { Negatif } \\
\text { Bentuk }\end{array}$ \\
$\begin{array}{l}\text { Kristal atau } \\
\text { serbuk }\end{array}$ \\
\hline
\end{tabular}

Sumber: Dewan SNI, 1995.

Oleh karena itu gula kelapa, baik yang berbentuk kristal atau bukan dapat dijadikan sebagai alternatif untuk kekurangan gula nasional. Selain itu gula kelapa merupakan produk yang baik dikonsumsi untuk menjaga kesehatan bagi manusia karena memiliki keunggulan. Hal ini disebabkan karena kandungan akan sukrosa yang terdapat dalam gula pasir lebih tinggi jika dibandingkan dengan kandungan sukrosa pada gula kelapa sehingga baik dikonsumsi untuk penderita diabetes. Selain itu kondisi saat ini masyarakat saat ini mulai menyadari akan pentingnya pola hidup yang sehat yang ditandai dengan mengkonsumsi produkproduk yang alami. Oleh karena itu gula kelapa yang merupakan salah satu produk yang diolah secara alami mempunyai peluang yang sangat tinggi untuk mengisi kekurangan akan gula secara nasional.

Kelompok pengrajin gula kelapa di

Desa Karangjengkol Kecamatan Kesugihan sudah tergabung dalam kelompok usaha Rengganis dengan ketua Pak Sardiman. Para pengrajin yang tergabung dalam kelompok usaha Rengganis sudah memproduksi gula kelapa dalam bentuk gula kelapa kristal, atau yang sering dikenal dengan gula semut. Pohon kelapa yang dideres umumnya sudah berumur lebih dari 50 tahun sehingga produksi nira yang dihasilkan tidak maksimal. Produksi gula kelapa kristal yang dihasilkan pengrajin di Desa Karangjengkol rata-rata $1-3$ ons per pohon/hari. Para pengrajin gula kelapa di Desa Karangjengkol mengelola pohon kelapa untuk di deres berkisar antara 30 
sampai 55 pohon kelapa. Pohon kelapa yang ada umumnya dibudidayakan di kebun sekitar rumah. Namun sayangnya pohon kelapa yang dideres oleh para pengrajin bukanlah pohon kelapa milik pengrajin gula kelapa. Pohon kelapa tersebut umumnya milik orang lain yang tingkat kesejahteraannya biasanya lebih baik dari para pengrajin gula kelapa sehingga tidak mau menderes. Sistem pengelolaan hasil gula kelapa yang terjadi umumnya dengan sistem sewa dan kontrak. Sistem sewa yang dimaksud adalah hasil dari produksi gula kelapa dalam 4 (empat) hari untuk si pengrajin gula kelapa dan 1 (satu) hari berikutnya hasil gula kelapa tersebut untuk si pemilik pohon kelapa. Sedangkan sistem kontrak adalah pengrajin gula kelapa melakukan kontrak perjanjian dengan pemilik pohon kelapa untuk jangka waktu dan harga kontrak tertentu. Jangka waktu kontrak umumnya adalah 1 (satu) tahun dengan harga kontrak berkisar antara Rp.75.000 - Rp.100.000 per pohon. Harga kontrak umumnya ditentukan oleh kualitas pohon kelapa yang akan dideres. Semakin berkualitas pohon kelapa yang akan dideres semakin mahal harga kontrak yang disepakati, dikarenakan kualitas pohon kelapa yang dideres akan menentukan banyak sedikitnya jumlah nira yang dihasilkan sehingga pada akhirnya berpengaruh terhadap jumlah gula kelapa yang dihasilkan.

Berdasar uraian tersebut di atas maka kegiatan ini bertujuan untuk meningkatkan pengetahuan dan ketrampilan petani tentang pembuatan gula kelapa kristal yang memenuhi standar Good Manufacturing Practice (GMP) dan Hazard Analysis and Critical Control Points (HACCP).

\section{METODE KEGIATAN}

Kelompok Usaha Bersama (KUB) Rengganis yang berada di Desa Karangjengkol berjumlah kurang lebih sebanyak 150 pengrajin. Khalayak sasaran yang diikutkan dalam kegiatan ini adalah para pengurus KUB Rengganis (sebanyak 10 orang) dengan harapan nantinya dapat menyampaikan hasil kegiatan kepada para anggota lainnya. Pekerjaan utama para pengrajin gula kelapa kristal tersebut adalah sebagai petani, sedangkan kegiatan pembuatan gula kelapa kristal merupakan pekerjaan sampingan. Umur rata-rata petani pengrajin 52,5 tahun dengan latar belakang pendidikan sebagian besar $42,1 \%$ hanya tamat sekolah dasar.

Untuk meningkatkan pengetahuan petani tentang peluang, mutu, dan standar gula kelapa kristal, maka metode kegiatan yang digunakan adalah ceramah. Materimateri penyuluhan yang diberikan mengenai peluang usaha gula kelapa kristal, pentingnya usaha secara berkelompok, standar produk gula kelapa yang sesuai dengan Good Manufacturing Practices (GMP), dan Hazard Analysis and Critical Control Points (HACCP). Sedang untuk meningkatkan ketrampilan petani terutama mengenai pembuatan gula kelapa kristal yang sesuai dengan standar maka kegiatan dilakukan dengan praktek secara bersama-sama. Praktek pembuatan gula kelapa kristal dilakukan di rumah ketua kelompok selama 3 hari, dimulai dari proses pemasakan nira sampai dengan menjadi gula kelapa kristal.

\section{HASIL DAN PEMBAHASAN}

Pekerjaan membuat gula kelapa adalah pekerjaan yang penuh dengan risiko, terutama pada tahapan menderes nira. Tahapan menderes nira adalah proses pengambilan nira di pohon kelapa. Pengambilan nira di atas pohon kelapa dilakukan dengan memanjat pohon yang ketinggiannya berkisar antara 5-10 meter. Pada saat musim hujan kondisi pohon kelapa yang licin menyebabkan risiko untuk jatuh dari pohon kelapa. Selain itu untuk dapat memanjat pohon kelapa dalam jumlah yang banyak (seorang penderes biasanya harus memanjat pohon kelapa sebanyak 20-30 batang) diperlukan kondisi 
badan yang betul-betul sehat. Risiko pekerjaan inilah yang oleh para penderes sangat diharapkan untuk mendapatkan perhatian.

Peningkatan pengetahuan pengrajin gula kelapa kristal mengenai GMP dan HACCP dalam pembuatan gula kelapa kristal ditunjukkan dengan kemampuan pengrajin menjelaskan mengenai tahapan pembuatan gula kelapa kristal yang sesuai dengan standar. Proses pembuatan gula kelapa kristal melalui beberapa tahap, pertama proses penyadapan nira. Nira disadap dengan menggunakan pongkor, sebelum dipasang, pongkor diberi laru organik yang terdiri dari air kapur dan tatal nangka. Sebelum dimasak nira terlebih dahulu disaring untuk menghilangkan kotoran. Tahap kedua adalah pemasakan nira di atas tugku sampai diperoleh nira yang kental. Pada saat pemanasan untuk mengurangi timbulnya buih, maka ditambahkan sedikit minyak kelapa atau santan. Tahap ketiga adalah pendinginan, nira kental diangkat dari atas tungku, kemudian didinginkan perlahan dengan udara terbuka. Selama proses pendinginan nira kental diratakan ke seluruh permukaan wajan sambil dibolak balik. Tahap keempat adalah pengkristalan. Setalah dingin akan terbentuk kristal gula, agar kristal gula tidak tumbuh, maka gumpalan-gumpalan gula di haluskan dengan dengan menggunakan tempurung kelapa. Selanjutnya kristal gula diayak untuk mendapatkan ukuran yang diinginkan. Tahap Kelima adalah pengeringan, setelah diayak, gula Kristal kemudian dikeringkan pada panas matahari sampai diperoleh gula kelapa kristal yang kering.

Dalam proses pembuatan gula kelapa kristal, para pengrajin di Karangjengkol sudah tidak lagi menggunakan larutan $\mathrm{Na}_{2} \mathrm{SO}_{4}$ sebagai bahan pencampur nira, ini menunjukkan bahwa sudah mulai ada kesadaran bahwa penggunaan bahan kimia sangat bertentangan dengan kaidah dalam GMP.
Hal ini sejalan dengan hasil penelitian yang dilakukan oleh Marsigit (2005) yang menyimpulkan bahwa pemberian bahan tambahan pada nira akan menyebabkan kualitas gula kelapa yang dihasilkan tidak akan memenuhi syarat SNI. Pemberian bahan tambahan sebaiknya menggunakan bahan alami, seperti kulit buah manggis, daun cengkeh, dan daun jambu biji, (Naufalin, et al, 2013).

Pengaturan lingkungan yang bersih di sekitar lokasi produksi masih perlu ditingkatkan agar terhindar dari cemaran yang dapat merusak nilai kesehatan produksi gula semut, meskipun hal ini sedikit menemui kendala karena lokasi produksi berada di tengah-tengah permukiman warga dan perpohonan yang relatif banyak menghasilkan sampah. Sehingga perlu diberi alternatif pengadaan lokasi pembuangan sampah yang cukup jauh dari lokasi produksi. Tata letak untuk proses produksi sudah memenuhi standar.

Sebagian besar konstruksi bangunan tempat produksi gula semut masih berupa bangunan tanpa dinding, lantai tanah dan tanpa cerobong asap. Bangunan tanpa dinding dibuat agar asap yang terbentuk pada proses pembakaran bisa segera tertiup angin, namun proses pembakaran kayu yang tidak sempurna dapat menghasilkan jelaga yang menempel di langit-langit bangunan dan sangat mengotori bangunan tempat produksi gula semut. Pengalihan dari bahan bakar kayu ke gas akan dapat mengurangi dampak negatif dari pencemaran jelaga di lokasi produksi tetapi hal ini perlu dilakukan pengkajian mengenai tingkat efisiensinya mengingat harga gas yang cukup mahal.

Sebagian besar peralatan yang digunakan sudah mengarah pada standard GMP kecuali wadah nira yang masih menggunakan ember PVC atau kaleng plastik bekas cat. Penggunaan pongkor bambu sebagai wadah nira lebih aman dari proses pencemaran, namun pongkor bambu sangat tidak tahan lama terutama pada 
kondisi cuaca yang terik akan mudah pecah sehingga nira yang tertampung akan tumpah. Oleh karena itu perlu dicari solusi teknologi penggunaan pongkor yang kuat dan higienis. Namun demikian walaupun sudah menggunakan peralatan yang sesuai namun kebersihan dari alat tersebut harus tetap dijaga agar populasi mikroba dalam pongkor dapat dikurangi sehingga inversi sukrosa menjadi gula reduksi dapat ditekan, (Sudewo et al., 2000).

Sanitasi petugas merupakan aspek yang masih perlu diperbaiki karena ratarata petani yang memproses gula semut merupakan penduduk dengan tingkat perekonomian yang rendah sehingga kurang memperhatikan performance dan sanitasi pada saat melakukan pemanasan nira, penggerusan, penyaringan dan penjemuran gula semut. Sebagian besar anggota KUB Rengganis sudah melakukan pengemasan produk yang sesuai dengan standar. Kemasan gula kelapa sebaiknya menggunakan bahan yang higroskopis atau dapat menggunakan kemasan plastik (Naufalin, et al., 2013).

Penerapan HACCP dalam industri gula kelapa kristal pada KUB Rengganis masih harus lebih ditingkatkan lagi. Hal ini mengingat kemungkinan-kemungkinan adanya bahaya cemaran pada produk yang dihasilkan. Penerapan HACCP dapat dialkukan dengan penyusunan Standard Operating Procedure (SOP) dalam pembuatan gula kelapa (Muchaymien et al., 2014). Bahaya/cemaran yang berpotensi muncul pada proses pembuatan gula kelapa kristal dapat dikategorikan sebagai berikut:

1. Bahaya Kimia

a. Penggunaan pongkor dari plastic non food grade yang akan menyebabkan terlarutnya polymer pongkor yang digunakan.

b. Penggunaan wajan yang kurang baik/karatan yang akan menyebabkan gula kelapa Kristal tercemar oleh logam dari wajan yang terkikis. c. Penggunaan dapur yang kurang sehat yang akan memungkinkan asap yang terbentuk dari bahan bakar akan mencampuri nira selama proses pemasakan.

2. Bahaya Mikrobiologis

a. Proses pendinginan dan pengkristalan gula yang dilakukan secara manual yang akan menyebabkan keringat akan jatuh ke gula kelapa kristal

b. Proses pengeringan yang hanya dipanaskan dengan menggunakan panas matahari secara terbuka yang akan menyebabkan masuknya jamur atau mikroorganisme lain dalama gula kelapa kristal yang diperoleh.

\section{SIMPULAN}

\section{Simpulan}

Berdasarkan pada hasil kegiatan yang dilaksanakan terhadap pengrajin gula kelapa kristal pada KUB Rengganis Desa Karangjengkol, maka dapat disimpulkan bahwa pengetahuan pengrajin mengenai aspek Good Manufacturing Practice (GMP) dan Hazard Analysis and Critical Control Points (HACCP) mengalami peningkatan yang ditunjukkan dengan kemampuan pengrajin untuk menjelaskan tahapan pembuatan gula kelapa kristal yang sesuai standar.

Peningkatan ketrampilan pengrajin dalam penerapan GMP dan HACCP mengalami peningkatan yang ditunjukkan dengan kemampuan para pengrajin pada saat praktek pembuatan gula kelapa kristal. Namun demikian penerapan GMP dan HACCP dalam industri gula kelapa kristal di KUB Rengganis Desa Karangjengkol belum sepenuhnya dapat dilaksanakan karena adanya berbagai keterbatasan yang dimiliki oleh para pengrajin.

\section{UCAPAN TERIMA KASIH}

Tim pelaksana kegiatan mengucapkan terima kasih kepada PT. Adhi Pratama dan LPPM Universitas Muhammadiyah Purwokerto atas pembiayaan kegiatan ini. 
Watemin, Agus Mulyadi Purnawanto \& Anwar Ma'ruf, Pelatihan GMP dan HACCP Bagi Pengrajin Gula Kelapa Kristal

\section{DAFTAR PUSTAKA}

Dewan Standarisasi Nasional. (1995). SNI: Gula Kelapa Kristal SII 0268-85. Dewan Standarisasi Nasional, Jakarta.

Marsigit, W. (2005). Penggunaan Bahan Tambahan pada Nira dan Mutu Gula Aren yang Dihasilkan di Beberapa Sentra Produksi di Bengkulu. Jurnal Penelitian UNIB, XI(1), $42-48$.

Muchaymien, Y., Rangga, A. dan Nuraini, F. (2014). Penyusunan Draft Standard Operating Procedure (SOP) Pembuatan Gula Merah Kelapa (Studi Kasus di Pengrajin Gula Merah Kelapa Desa Purworejo Kecamatan Negeri Katon Kabupaten Pesawaran. Jurnal Teknologi Industri dan Hasil Pertanian, 19(2), 205 - 217.

Naufalin, R., Yanto, T., dan Sulistyaningrum, A. (2013). Pengaruh Jenis dan Konsentrasi Pengawet Alami terhadap Mutu Gula Kelapa. Jurnal Teknlogi Pertanian 14(3): 165 - 174.

Naufalin, R., Sustriawan, B., Sakhidin, Sularso, K.E., dan Yanto, T. (2013). Desain Bentuk dan Kemasan untuk Mempertahankan Mutu Gula Kelapa. Jurnal Pembangunan Pedesaan, 13(1), $57-66$.

Sudewo, A., Y. Praptiningsih, dan Tamtarini. (2000). Pengaruh Pengaturan $\mathrm{pH}$, Penambahan Sukrosa, Bentuk Cetakan dan Pengemas Klaras terhadap Kualitas dan Umur Simpan Gula Kelapa. Seminar Nasional Industri Pangan.
Perhimpunan Ahli Teknologi Pangan Indonesia, Surabaya.

Yusuf, Y., Martadi, S., \& Aulia, A. (2010). Permintaa Gula Pasir Indonesia. Pekanbaru: Jurusan Ilmu Ekonomi, Fakultas Ekonomi, Universitas Riau . 